\title{
Economia criativa: \\ o caso das Incubadoras \\ Rio Criativo frente às \\ políticas culturais tradicionais
}

\author{
Ruth Mello \\ Julia Zardo ${ }^{1}$
}

\begin{abstract}
Resumo
O caso da política pública das Incubadoras Rio Criativo é foco deste artigo. A vanguarda e os resultados de iniciativa governamental inspiraram a criação política nacional de incubadoras criativas por parte do Ministério da Cultura. A abordagem histórico-conceitual desse processo no mundo e no Brasil oportuniza tratar de questões como as circunscritas no debate das tipologias e natureza das políticas culturais, assim como sobre as implicações do enfoque de mercado aos empreendimentos criativos frente à natureza de transcendência e gratuidade das expressões e manifestações culturais. Estas políticas são relevantes pela maior visibilidade e escala que têm dado a práticas e conteúdos sobre empreendedorismo inovador a agentes culturais, configurando tais políticas como ações complementares às iniciativas governamentais tradicionalmente observadas.
\end{abstract}

Palavras-chave: cultura; economia criativa; políticas públicas; Rio de Janeiro; Rio Criativo

\begin{abstract}
Absract
Rio Criativo public policy study case is focus of this article. The vanguard and results of this governmental initiative inspired the creation of the national policy named Creative Incubators Network by Ministry of Culture. The historical-conceptual approach of this process in the world and in Brazil provides an opportunity to deal with issues such as the discussion of the types and nature of cultural policies, as well as market implications to the creative entrepreneurs toward the transcendence and gratuity nature of cultural expressions. These policies are relevant for greater visibility and scale considering the practices and contents on innovative entrepreneurship to cultural agents, configuring as complementary actions to government initiatives traditionally observed.
\end{abstract}

Keywords: culture, creative economy, public policies, Rio de Janeiro, Rio Criativo

1 Ruth Espinola Soriano de Mello, economista doutoranda em Ciências Sociais pela PUC-Rio, professora da PUC-Rio e assessora da Gerência de Cultura Empreendedora do Instituto Gênesis da PUC-Rio. uth@puc-rio.br

Julia Bloomfield Gama Zardo, graduada e mestre em Comunicação, doutoranda em Políticas Públicas, Estratégias e Desenvolvimento pelo IE/UFRJ, professora da PUC-Rio e gerente de Cultura Empreendedora do Instituto Gênesis da PUC-Rio. uliaz@puc-rio.br 


\section{Introdução}

A produção e gestão cultural do Estado na sociedade contemporânea tem ocorrido de forma diferenciada ao longo da história. Ora assumindo caráter intervencionista - orientando e conduzindo a organização da produção -; ora se restringindo ao papel de parceiro da cultura, fornecendo subsídios e suporte, sem interferir sobre os conteúdos de forma direta. Esse último cenário é o que parece imperar na atualidade (Ortiz Ramos e Bueno, 2001).

É possível observar que a economia mundial passou a lançar mão da produção cultural em seus domínios desde o final do século XX. Durante os anos 1960, no pós-guerra, o processo de consolidação do setor cultural como vetor econômico foi observado como um fenômeno de êxito, pelo menos para os países tidos como desenvolvidos. Tal desempenho estava diretamente associado à ação conjunta do binômio Estado e mercado, especialmente para segmentos com cadeias produtivas de larga extensão como o audiovisual.

Naquele período, o desenvolvimento do sistema de comunicação e a desterritorialização da indústria cultural teriam sido determinantes para a expansão da fronteira da cultura para além do entretenimento e do prazer estético. Assim, a arte e a cultura teriam se transformado, "de simples redutos de lazer numa das principais esferas de construção de identidades” (Ortiz Ramos e Bueno, 2001:11).

Para os países periféricos, as políticas culturais² vivenciaram dinâmica histórica que merece uma análise aprofundada que foge ao escopo deste artigo. Não obstante, podemos afirmar que, no Brasil, as políticas culturais se identificaram com a referência do modelo francês em que o Estado tem protagonismo no financiamento das diversas expressões da cultura. Outro modelo possível seria o observado nos Estados Unidos da América em que a sociedade e o setor privado aparecem com maior destaque em detrimento da atuação do setor público que teria papel secundário (Saraiva, 1999:90 apud Ismael, 2004). No Brasil, as políticas dependem historicamente de recursos disponíveis nos orçamentos dos três níveis federativos, ${ }^{3}$ assim como da disposição das empresas privadas e estatais, interessadas em apoiar a área cultural via leis de incentivos fiscais em troca de renúncia fiscal.

É neste cenário que as políticas públicas direcionadas ao setor criativo estão sendo implementadas recentemente no Brasil, enriquecendo o debate sobre a natureza da intervenção e inter-relação do Estado, da sociedade e do mercado em sua concepção e implementação.

Adicionalmente, para evidenciar a importância da economia criativa em nível mundial e nacional, seguem dados reveladores. A Internacional Trade Center (ITC) indica que a economia criativa representa mais de 7\% do PIB mundial, US\$1,3 trilhão anualmente, tendo uma taxa de crescimento de $9 \%$ ao ano (ITC, 2014). Tratamos aqui da terceira maior indústria do mundo, posicionada depois da indústria do petróleo e de armamentos $^{4}$ (Folha de São Paulo, 2011).

\footnotetext{
Os países em desenvolvimento representam apenas 1\% do total das exportações, apesar de sua rica herança cultural e abundância de talento. O desenvolvimento do setor de indústrias criativas não é apenas um mecanismo para aumentar a participação dos países em desenvolvimento no comércio mundial, mas também pode beneficiar diretamente as comunidades pobres através da geração de renda, criação de empregos e capacitação de artistas e pessoas. (ITC, 2014, tradução nossa)
}

\footnotetext{
2 Políticas culturais entendidas como o conjunto coordenado e coerente de preceitos e objetivos que orientam linhas e ações públicas mais imediatas no campo da cultura (Calabre, 2005:2).

3 Estados e municípios possuem competência suplementar com relação à legislação cultural, cabendo à União a definição das normas gerais (Velloso, 1992:16 apud Ismael, 2004), sendo poucas as iniciativas observadas em que os entes federativos operam de forma orquestrada e complementar. 
No Brasil, o setor movimenta mais de R\$ 667 bilhões anualmente - correspondendo a 18\% do PIB nacional, segundo apuração da Federação das Indústrias do Estado do Rio de Janeiro (FIRJAN, 2010) que se valeu de dados formais do número de empregados e respectiva remuneração segundo uma metodologia que considerava os setores do núcleo, ${ }^{5}$ das atividades relacionadas ${ }^{6}$ e de apoio ${ }^{7}$ associadas ao setor criativo nacional.

Adicionalmente, em 2011, eram 243 mil empresas que conformavam o núcleo da indústria criativa nacional, cuja massa salarial associada era de cerca de R 110 bilhões, 2,7\% do PIB. O mercado formal era de 810 mil trabalhadores, 1,7\% do total de empregados em 2011, sendo o setor de engenharia e arquitetura o de maior concentração.

Não obstante, tem-se que os dados apresentados da economia criativa não respondem pela dimensão real da circulação doméstica de produtos e serviços criativos, dado o alto grau de informalidade da economia brasileira, ainda que, em relação ao mercado de trabalho total, a informalidade seja menor no mercado de trabalho cultural, variando de 38 a 55\%, dependendo dos parâmetros adotados (Mello e Zardo, 2014).

Mesmo assim, os dados oficiais do estado fluminense apontam que a cadeia produtiva da indústria criativa representa pelo menos $\mathrm{R} \$ 76,3$ bilhões, empregando mais de 973 mil pessoas nas atividades relacionadas, de apoio e do núcleo. Considerando apenas as atividades do núcleo, o setor criativo representa, no Estado do Rio de Janeiro, 2,2\% do trabalho formal fluminense, ficando apenas abaixo de São Paulo no hanking nacional (idem). Vale notar que os dados são sobremaneira relevantes, sendo a metodologia de apuração amplamente aceita por estatísticos, embora seriam ainda mais expressivos se se considerasse a informalidade comum àqueles setores identificados na metodologia.

Nesse mesmo contexto, tem-se que os microempreendimentos possuem um relevante papel no cenário econômico do país como um todo e são ainda mais importantes no campo das indústrias criativas. As atividades do núcleo, relacionadas e de apoio da cadeia fluminense apontam, respectivamente, 85\%, 91\% e 94\% como parcelas das empresas com menos de 20 empregados (microempresa), seguidas de longe pelas empresas de médio porte (20 a 99 empregados) (Rais, 2006 apud FIRJAN, 2008).

Das quatorze profissões consideradas na pesquisa, em oito os profissionais fluminenses ganham mais que os demais; ressalte-se também que o salário médio dos trabalhadores criativos no Estado do Rio de Janeiro é de R\$ 7.275, mais de quatro vezes superior à média nacional, sendo a melhor remuneração da Indústria Criativa brasileira (FIRJAN, 2012).

Esta Introdução buscou contextualizar o cenário em que a dinâmica da economia solidária e das políticas a ela circunscritas se insere, tendo iniciado com uma breve categorização histórica acerca das tipologias das políticas culturais de modo a identificar as que dialogam com a história do nosso país nesse contexto, especialmente considerando as novas políticas do setor que passaram a abranger a economia criativa.

A seção seguinte apresenta referencial teórico da economia criativa que está se consolidando internacionalmente desde o final do século passado. Segue-se em uma trajetória conceitual do termo no Brasil, buscando-se apontar sua escala no escopo das políticas públicas governamentais. Ambas as seções teóricas, internacional e nacional, aqui citadas serão enredadas a partir de questões-chave como a temática da visão de mercado vis-à-vis a

5 Como sendo as atividades que têm a criatividade como parte principal do processo produtivo (FIRJAN, 2012).

6 Os segmentos de provisão direta de produtos e serviços ao núcleo e compostos, em grande parte, por indústrias e empresas de serviços e fornecedoras de materiais e elementos fundamentais para o funcionamento do núcleo (FIRJAN, 2012).

7 Atividades que englobam provisão de produtos e serviços de forma indireta (FIRJAN, 2012). 
via da experimentação, da transcendência das expressões artísticas, normalmente emoções gratuitas, não instrumentais.

O papel das incubadoras no Brasil no apoio a empreendimentos culturais é então apresentado de modo a dar cena ao caso do Instituto Gênesis da PUC-Rio, primeira incubadora cultural no continente latinoamericano (2002), a qual passou a abraçar o termo das indústrias criativas em seus programas de cultura empreendedora e de geração de negócios inovadores em setores que extrapolavam o conceito anterior de economia da cultura. $\mathrm{O}$ enfoque da seção também se justifica pelo fato de que, por sua vanguarda e expressividade dos seus resultados, o Gênesis também recebeu tal destaque por ter chamado a atenção da Secretaria de Estado de Cultura do Rio de Janeiro para conceber e implementar o Rio Criativo, em 2009.

O Projeto Rio Criativo, em especial as incubadoras de empreendimentos criativos a ele relacionadas, passa a ser o objeto da seção seguinte deste artigo. O projeto foi relevante para políticas públicas que seguiriam a ele em nível nacional, tal qual a incubadora cultural do Gênesis foi para o universo das incubadoras brasileiras. O Rio Criativo veio a inspirar a política nacional do Ministério da Cultura (MinC) quando da criação e implantação do Programa Rede Incubadoras Brasil Criativo. Assim, o Rio Criativo é abordado desde a concepção até a finalização do ciclo do primeiro grupo de empreendimentos que completou o tempo de incubação previsto; também apresentaremos dados do seu processo de formação público implementado em paralelo ao período de incubação.

Na última seção faremos as considerações gerais retomando o debate sobre a contribuição advinda da implementação de novas políticas culturais brasileiras que englobam o recorte conceitual da economia criativa. Elas têm se colocado de forma complementar às políticas tradicionais e imprimem escala absolutamente relevante ao estímulo ao empreendimento no setor criativo e na geração de novos negócios criativos nacionais.

\section{1 - Referencial teórico conceitual e implicações nas ações de artistas e agentes culturais}

Como visto brevemente, o século passado foi marcado por mudanças cujos efeitos seguem presentes, especialmente os que implicam a dita desmaterialização dos processos produtivos que passaram a incorporar com mais vigor a informação e o conhecimento, sobressaltando a supremacia dos conteúdos imateriais, simbólicos e intangíveis nas relações socioeconômicas.

Nesse contexto, observamos autores como Domenico de Masi (1999) que, ao analisar indivíduos e grupos criativos do período de 1850 a 1950, entende que vivemos, desde então, uma terceira onda denominada como uma "era pós-industrial" capaz de "exaltar a dimensão criativa das atividades humanas, privilegiando mais a cultura do que a estrutura [...]”. (De Masi, 1999:13).

O sociólogo italiano (De Masi, 1999:15), ao tratar da teoria das ondas longas históricas de Fernand Braudel, afirma que estas teriam passado a ficar cada vez mais curtas. Teriam sido necessários milênios para o advento do Estado moderno, mas apenas 500 anos para a organização da sociedade industrial. Menos da metade deste período teria sido vivenciada para a chegada da era pós-industrial, sendo esta ainda não difundida tampouco radicada integralmente; todavia, os novos tempos estariam apresentados para qualquer observador. Completa: 
[...] no mercado de trabalho, os ligados ao setor terciário já superam os que se dedicam à agricultura e à indústria reunidas; na formação do produto interno prevalecem os serviços sobre os bens materiais; no sistema social, o conhecimento teórico, a ciência e a informação agora ocupam o papel central que já pertenceu à produção manufatureira; no sistema cultural, o individualismo e o narcisismo adquirem vigor crescente, enquanto os gostos se desmassificam e as modas pegam cada vez menos; no sistema ideal, volta a emergir o senso estético como parâmetro para o valor das coisas. (De Masi, 1999:15, grifos nossos)

Como causa e efeito daquelas mudanças, a história recente marcou a concepção e emergência do conceito circunscrito à economia criativa no âmbito dos estudos culturais e dos debates sobre tendências do setor de serviços das economias globais.

Tal conceito está se consolidando de forma a imprimir valor econômico à cultura de forma que seja entendida, não apenas na identificação e preservação de tradições e diversidade, mas também representando vetor e recurso de desenvolvimento econômico.

George Yudice entende que a cultura passou a ser recurso de geração e atração de investimentos, fonte inesgotável para distribuição e utilização de setores econômicos (Yudice, 2006). Seria a teorização de algo que já estaria sendo constatado, isto é, "queira ou não" a arte - tradicionalmente observada como via de transcendência - seria usada para fins instrumentais. Teríamos assim o reconhecimento de que efetivamente a "cultura já não é mais arte", sendo esta a "ponta do iceberg da cultura". A cultura é entendida como a criatividade humana, lugar onde mais se manifesta a criatividade (Yudice, 2005).

\footnotetext{
Eu posso ser artista "puro", mas, quando eu colocar minha arte em um museu, estarei contribuindo com orçamento do PIB [Produto Interno Bruto] da cidade. Quando as pessoas pensam em criar um museu, elas justificam o museu pela arte, mas esse museu vai certamente contribuir para a economia da cidade. Então, queira eu ou não, a arte será sempre um recurso. (Yudice, 2005:3)
}

De posicionamento contrário a Yudice, Garnham (2005) defende a volta da centralidade do artista. A defesa da oferta de subsídios culturais por parte do Estado, com a estratégia de promoção da economia criativa, tem afetado seu principal objetivo que é o amplo acesso às políticas culturais.

De todo modo, como observado acima, os dados anteriormente citados da dinâmica da economia criativa revelam a importância crescente do conceito que surge associado às abordagens que identificam seu potencial de produtos, serviços e, por consequência, de emprego, renda e riqueza. Deriva-se daí sua importância no campo do conhecimento, do mercado e do Estado ao passar a apontá-la na agenda e desenvolvimento de políticas públicas, e mesmo nomeando pastas governamentais.

A primeira vez em que o termo economia criativa foi mencionado data de 1994, na Austrália, no âmbito da formulação de políticas públicas de estimulo à economia movida pela cultura e criatividade, intitulada Creative Nation. O programa australiano foi também a primeira ação federal do país no âmbito das políticas culturais, implementado pelo então primeiro-ministro Paul Keating . O programa apresentou a importância da identidade nacional e definiu assim a cultura de forma mais ampla em relação a conceitos pregressos, incluindo o setor do audiovisual, radiofônico, editorial, entre outros. Adicionalmente, apontou o potencial econômico da atividade cultural e das artes, seu caráter de atração turística, contribuição à inovação nacional, representatividade na balança de exportação, tal qual podemos ver mais detalhadamente neste trecho: 
Esta política cultural é também uma política econômica. Cultura cria riqueza. Em termos gerais, as nossas indústrias culturais geram US\$ 13 bilhões de dólares por ano. O setor emprega cerca de U\$ 336.000 australianos em indústrias relacionadas à cultura. Cultura agrega valor, faz uma contribuição essencial para a inovação, marketing e design. É um símbolo da nossa indústria. O nível de nossa criatividade determina substancialmente a nossa capacidade de adaptação a novos imperativos econômicos. É uma exportação valiosa em si mesma e um acompanhamento essencial para a exportação de outras mercadorias. Atrai turistas e estudantes. É essencial para o nosso sucesso econômico. (AUSTRÁLIA, 1994:1, tradução nossa)

Stuart Cunningham (2002) entende que o enfoque da economia criativa surgiu na Austrália por razão de a cultura ter se divorciado da política industrial mais do que em outros países. A ortodoxia econômica da década de 1980 teria impactado fortemente as políticas nacionais, tendo sido especialmente presente em nível federal. Ele entende que isso "resultou em duas décadas de árido argumento associado à separação da cultura (que tem base 'institucional') e do entretenimento (base 'industrial')” (Cunningham, 2002:9).

Três anos depois do surgimento do termo na Austrália, em 1997 o New Labour, partido trabalhista inglês, o abordou em seu manifesto pré-eleitoral. ${ }^{9} \mathrm{O}$ termo foi então mundialmente popularizado com a vitória eleitoral, em 1998, desse partido que instaurou em seu mandato a criação de uma força-tarefa inglesa, sob a coordenação direta de seu primeiro-ministro, Tony Blair, que implementou, entre outras ações, o mapeamento de setores econômicos do setor criativo cultural para além do escopo tradicional da cultura; a revisão do sistema educacional; a valorização do intangível cultural por parte de instituições financeiras; a revisão da estrutura econômica, de cadeias setoriais para redes de valor (DCMS, 2001).

A partir daquele momento, o termo inglês para economia criativa era apresentado como as "indústrias que têm sua origem na criatividade individual, na habilidade e no talento e que têm um potencial de riqueza e criação de emprego através da geração e exploração da propriedade intelectual” (DCMS, 2001:4).

As ações da força-tarefa inglesa explicam o porquê da popularidade para além da vanguarda da iniciativa. Conforme aponta Ana Carla Reis, o mérito inglês reside também no fato de que propiciou a "parceria entre o público e privado de modo a desenhar um programa estratégico com benefícios, responsabilidades compartilhadas, articulações transversas, compreendendo diferentes setores e pastas públicas [...]” (Reis, 2008:17).

No entanto, apesar da crescente importância do tema na agenda governamental de diversos países e diretrizes de órgãos supranacionais, seu conceito ainda não está consolidado nacional nem internacionalmente.

As primeiras publicações sobre este tema surgiram a partir de $2000 \mathrm{com}$ destaque para os seguintes autores: Seltzer Bentley, Richard Caves, John Howkins, John Hartley, Stuart Cunnigham, Richard Florida.

Reis (2008) afirma que a economia criativa traz vestígios conceituais que se fundem configurando um único: da economia da experiência, detém a originalidade; dos processos colaborativos, utiliza os aspectos intangíveis na geração de valor, fortemente ancorada na cultura e em sua diversidade; da economia do conhecimento, partilha o foco no trinômio tecnologia/mão-de-obra capacitada/geração de direitos de propriedade intelectual; da economia da cultura, o novo termo propõe a valorização da autenticidade e do intangível cultural.

Miguez (2007) argumenta que ambas as expressões - indústria criativa e economia criativa - tratam do mesmo objeto, sendo ambas alcançadas pelo expressivo debate das disciplinas 
científicas da "terceira revolução industrial”, estando assim conectadas a uma variada gama de denominações que visam capturar o paradigma de produção da sociedade contemporânea.

Xavier (2008) extrapola a questão conceitual e descritiva do termo e analisa a cultura digital e as redes colaborativas como oportunidades para empreendedores criativos, de forma a impactar no mercado a partir de novos negócios da economia criativa. Entende que há modelos inovadores de negócios possíveis nos tempos contemporâneos com a emergência das indústrias criativas. Tais oportunidades seriam diferentes dos padrões vivenciados até então. Seria um modelo com bases colaborativas, que exige uma visão mais abrangente, como também a própria revisão do conceito de concorrência. A concorrência eletrônica seria notadamente sempre global. Basta um clique para acessar concorrentes e parceiros. Identifica como positivos os novos canais de relacionamento direto com os clientes, os quais permitiriam aperfeiçoar os produtos de forma constante. Por isso, o conhecimento de ponta seria essencial (Xavier, 2008).

Retomam-se, como exemplo, os aportes datados de 1944 de Adorno e Horkheimer (2006) - representantes da Escola de Frankfurt -, para os quais os setores culturais - cinema, rádio, TV, teatro, design, arquitetura e moda - passaram a ser observados como expressões artísticas de agregação de valor econômico de forma a serem tomados como negócios promissores. Tal debate se inscrevia no momento inicial sobre a industrialização da cultura, de forma a fazer da cultura uma mercadoria, um bem de consumo. Esta nova indústria teria padrões que se repetiriam para configurar uma estética ou percepção comum para o consumo.

\footnotetext{
Com efeito, ao apontar os perigosos reflexos dos avanços tecnológicos contemporâneos [meados do século XX] no campo da subjetividade, os autores configuram aqui uma problemática que não se refere somente à atividade científica, mas ao próprio sentido desta última em um padrão cultural que transforma o pensamento em mercadoria e a linguagem no seu mero encarecimento. (Souza, 2011:1)
}

Não obstante, faz-se mister ressaltar que há enfoque coerente ao observar e compreender as diversas iniciativas do campo da arte e cultura vis-à-vis a ineficácia histórica das ações de estímulo e regulação da res publica do campo da cultura - setor tão caro por abranger a identidade, diversidade entre outros aspectos que respondem pela própria natureza humana. Tal argumento merece, no entanto, lembrança de que a espontaneidade das expressões humanas também oferece a oportunidade do necessário distanciamento do Estado - dinâmica saudável de construção e manutenção de uma crítica exógena dos agentes culturais e consumidores de cultura, frente às ações do Estado, financiadas com recursos de todos para todos.

Adicionalmente Ronaldo Fiani (2013) retoma o debate sobre o fenômeno da doença dos custos da qual a economia criativa também seria vítima (junto com outros nobres setores da sociedade como o da saúde e educação). Fiani afirma que Baumol teria solucionado de forma muito simplista a temática:

\footnotetext{
Como os produtos industrializados vão ficar cada vez mais baratos e os produtos culturais cada vez mais caros, o que vai acontecer é que as pessoas vão gastar uma parcela cada vez menor do seu orçamento em bens industrializados e uma parcela cada vez maior do seu orçamento em bens culturais e serviços pessoais, tais como educação e saúde. Como mesmo onde a produtividade cresce menos - como as atividades culturais - ela mesmo assim ainda cresce, as pessoas poderão pagar por esses bens e serviços. Elas apenas vão mudar espontaneamente seus gastos, por assim dizer, de automóveis e computadores para espetáculos musicais e peças de teatro. (FIANI, 2013:4)
}

Fiani, uma vez tendo aceitado a teoria de Baumol da doença dos custos para o setor cultural, levanta questões intrigantes: as pessoas passariam a gastar menos em produtos in- 
dustrializados e mais em bens culturais? Quais seriam os consumidores que consumiriam os bens culturais, e que bens culturais seriam estes? (idem)

Uma análise superficial pode levar a crer que a economia criativa seria uma ampliação contemporânea da economia da cultura, assim como a economia da cultura pode ser identificada enquanto extensão dos limites que circunscreveram a economia das artes. Porém, todos os conceitos são singulares e de alguma forma agregam características específicas. Entendemos, corroborando com Miguez (2007), que as indústrias criativas são tanto um "setor individualizado no conjunto da economia, como também um setor que amplia o campo de alcance das relações entre cultura e economia” (Miguez, 2007:12).

\section{2 - Processo de consolidação do conceito e das políticas no Brasil}

Em 2004, quando da realização da XI Conferência da UNCTAD, em São Paulo, as indústrias criativas são tratadas pela primeira vez em um painel exclusivo relacionado à perspectiva dos países em desenvolvimento. Tal evento foi um marco não apenas para o Brasil, já que as recomendações do painel influenciaram nas agendas de organizações supranacionais.

Desde então, a consolidação do termo economia criativa vem ocorrendo de forma a dar relevância aos papéis em que a cultura se insere especialmente por sua interferência como vetor de desenvolvimento socioeconômico local: cultura como identidade formadora de um povo; enquanto marca diferenciadora de um território; e configurando indústria criadora de valor tangível e intangível para bens e serviços.

Tal tese é referendada pelo então ministro da Cultura no Brasil, Gilberto Gil, para quem a cultura é tanto dimensão simbólica da existência social de um povo, eixo construtor das identidades, espaço privilegiado de realizações da cidadania e inclusão social, como pelo fato econômico de geração de renda e riquezas (UNESCO, 2002).

Vale mencionarmos que, diferente do conceito que vem se consolidando em nível internacional com base no modelo inglês, o termo e as políticas que estão sendo desenhadas há poucos anos em solo brasileiro têm estado mais ligadas aos processos de criação e de produção tendo como pano de fundo a diversidade cultural. Logo, menos atentas à propriedade intelectual de bens ou serviço como no modelo fundido no Reino Unido.

Em 2007, observamos a mudança conceitual da cultura em publicação do Instituto Brasileiro de Geografia e Estatística (IBGE) em parceria com o MinC - "Sistema de Informações e Indicadores Culturais de 2007 a 2010” (IBGE, 2013) - em consonância com a concepção da Unesco ao apontar aquelas atividades relacionadas:

\footnotetext{
à criação e produção, tradicionalmente ligadas às artes, como teatro, música, filme, edição de livros, fotografia, rádio, televisão, bibliotecas, arquivos, museus e patrimônio histórico, que foram consideradas neste estudo como atividades diretamente relacionadas à cultura. Outro conjunto, mais abrangente, relacionado aos equipamentos e às atividades de suporte de informática do setor cultural, foi considerado como atividades indiretamente relacionadas à cultura (como a telefonia, a Internet, a fabricação de equipamentos transmissores de comunicação, entre outros), que agregam atividades propriamente culturais e outras que não podem ser caracterizadas como tais. (IBGE, 2013:8)
}

A construção do escopo institucional federal da economia criativa seguiria seu curso, apontando progressivamente para uma abordagem de percepção ampliada sobre o papel da cultura "enquanto produção simbólica, assumida com um direito de cidadania, como um 
fator e indicador de desenvolvimento econômico e como um elemento das agendas dos programas de desenvolvimento nacional”. (BRASIL, 2013:8, grifos nossos).

Em 2008, temos o primeiro dos três mapeamentos das indústrias criativas no Brasil que a Federação das Indústrias do Estado do Rio de Janeiro (Firjan) já publicou até hoje. Inicialmente seguiram o conceito inglês (DCMS, 2001) que serviu como base para a taxonomia das atividades econômicas apuradas, as quais foram organizadas segundo três atividades: atividades-núcleo - ideias como insumo principal; atividades relacionadas - provêm diretamente bens e serviços ao núcleo; e atividades de apoio - as que ofertam bens e serviços indiretamente ao núcleo (FIRJAN, 2008), como apresentado na primeira seção deste artigo.

O marco nacional no campo das políticas ocorreu com a Secretaria da Economia Criativa (SEC), vinculada ao MinC formalmente em 2012, um ano depois do lançamento do Plano Nacional de Cultura 2010-2020 (BRASIL, 2010) que foi estruturado em três dimensões: a cultura como expressão simbólica; como direito de cidadania; e, notadamente como campo potencial para o desenvolvimento econômico sustentável.

Essa última dimensão, em especial, deu base à formulação de inúmeras metas do Plano Nacional de Cultura (BRASIL, 2010), as quais têm sido implantadas sob diferentes políticas pelos entes federativos e atores nacionais que lograram receber recursos federais ou dispõem de recursos próprios. Destacam-se aqui as ações do governo do Estado do Rio de Janeiro que selou convênios que implicaram transferências de recursos voluntários no âmbito de ações no campo da economia criativa para o Estado. Tais recursos associados a recursos do tesouro do Estado foram particularmente substantivos na promoção do Projeto Rio Criativo.

Em 2012, a Secretaria Nacional de Economia criou o Plano da Secretaria da Economia Criativa - Políticas, Diretrizes e Ações de 2011 a 2014, em consonância com o "compromisso com o Plano Nacional de Cultura, Plano Brasil sem Miséria, na busca pela competitividade e da inovação dos empreendimentos criativos brasileiros" (BRASIL, 2012:5), já que, "apesar de ser reconhecido por sua diversidade cultural e potencial criativo, o Brasil não figura nas pesquisas entre os dez primeiros países em desenvolvimento, produtos e exportadores de bens e serviços criativos" (idem); sobressaindo mais uma vez a lógica da busca do ranking da competitividade internacional.

O Plano da Secretaria da Economia Criativa apresenta, entre outros, o vetor "empreendedorismo, gestão e inovação" em que é previsto fomento técnico e financeiro a empreendimentos via criação de incubadoras, birôs de serviços e linhas de financiamento (BRASIL, 2012:43). Também houve previsão do lançamento de edital de fomento de incubadoras universitárias estimulando ampliação do número de empreendimentos criativos; ação realizada em 2013.

Estudos têm sido realizados sobre o Plano Nacional e o Plano desta Secretaria. Como exemplo, Sharine Melo observa o enfoque do Estado na ação empreendedora ao analisar todas as metas apresentadas no Plano Nacional. De forma crítica, ela observa que, embora o Estado apontasse interesse em "estimular e apoiar a atuação empreendedora no âmbito da cultura” terminou não abraçando toda a diversidade dos agentes que atuam no campo criativo, como exemplo, o das artes (Melo, 2014:10). Mas, quanto à indicação de necessidade de profissionalização dos agentes culturais, a autora observa que a questão ganha relevância no Plano em detrimento de outras metas, indicando que "os artistas devem seguir uma lógica semelhante à das empresas, capazes de gerar recursos para manter suas próprias atividades, seus próprios negócios” (idem, p. 11).

Entendemos que, ao lançar mão das incubadoras como meio para implementar política 
pública de empreendedorismo inovador ao setor criativo, há um avanço em relação a práticas tradicionais do Estado, principalmente pela escala de abrangência da política que vinha sendo praticada no limite da atuação local de incubadoras e outros agentes que promovem empreendedorismo no Brasil. Assim, atualmente muito mais gente no Brasil conhece o empreendedorismo e pode tomar a decisão de empreender com mais informação e apoio.

Observarmos que a natureza conceitual das indústrias criativas e das políticas relacionadas dialogam com os objetivos das incubadoras de empresas que trabalham com o setor cultural e criativo. Esse argumento explica o porquê da próxima seção que trata da dinâmica das incubadoras no Brasil; das particularidades das que abrangem tais setores; da conjugação de fatores que culminou com a concepção e desenvolvimento no Estado do Rio de Janeiro da primeira incubadora criativa governamental.

\section{3 - O papel das incubadoras no apoio a empreendimentos culturais: o caso do Instituto Gênesis da PUC-Rio}

A história das incubadoras no Brasil é recente. Data da década de 1980 o surgimento das primeiras iniciativas então promovidas pelo Conselho Nacional de Desenvolvimento Cientifico e Tecnológico (CNPq), ao implantar o Programa de Parques Tecnológicos no país. Atualmente, o Brasil integra um dos "maiores sistemas mundiais de incubadoras" (ANPROTEC, 2012:5).

Inicialmente, elas buscavam atrair a geração de empreendimentos de base tecnológica com potencial de levar ao mercado ideias inovadoras e tendências tecnológicas em setores intensivos em conhecimento científico e tecnológico. Posteriormente, associavam também tal objetivo ao de apoiar desenvolvimento local e setorial (idem).

As incubadoras brasileiras se configuram enquanto atores que integram o ambiente de geração de empreendimentos inovadores, apoiando-os no momento mais relevante para sua manutenção no "mercado" após o processo de incubação, período conhecido como de graduação. Esse é o critério para associação junto à Associação Nacional de Entidades Promotoras de Empreendimentos Inovadores (Anprotec) que integra incubadoras de empresas, parques tecnológicos, instituições de ensino e pesquisa, órgãos públicos e outras entidades ligadas ao empreendedorismo e à inovação, tendo atualmente 280 associados, mas registrando a existência de cerca de 400 incubadoras de empresas e 90 iniciativas de parques tecnológicos no Brasil (ANPROTEC, 2014).

Incubadoras visam apoiar a geração e consolidação de pequenas e médias empresas (MPEs); ${ }^{10}$ estimular a identificação e o desenvolvimento do perfil empreendedor dos indivíduos envolvidos quanto aos aspectos técnicos, comportamental e gerencial; e facilitar o processo de empresariamento e inovação tecnológica em nível local.

As incubadoras no Brasil se caracterizam por ambientes que oferecem espaço físico para abrigar empreendimentos nascentes; ${ }^{11}$ disponibilizam infraestrutura e serviços compartilhados; promovem cursos, assessorias e consultorias para a gestão técnica e empresarial dos sócios e colaboradores; implementam estudos e pesquisas setoriais; oferecem informa-

10 MPEs no Brasil representam mais de $1 \frac{1}{4}$ do Produto Interno Bruto - PIB nacional e a maioria das empresas no país, sendo responsáveis por $53 \%$ do PIB de comércio do Brasil, $36 \%$ do setor de serviços e a $22 \%$ da indústria. Elas empregam contingente importante da população economicamente ativa, sendo identificadas como "colchão de amortecimento" de crises econômicas e elemento de flexibilização do capital e trabalho (Lastres et al., 2003).

11 Empreendimentos com três a cinco anos de existência. 
ções sobre acesso a mecanismos de financiamento por vias próprias ou de terceiros; brindam acesso a mercados e redes de inter-relações de suas incubadoras; disponibilizam laboratórios de pesquisa e de apoio à prototipação de produtos; implementam processo de acompanhamento, avaliação e orientação aos empreendimentos e empreendedores (ANPROTEC, 2012).

A Figura 1 ilustra a representatividade da oferta de infraestrutura e serviços no universo de quase 400 incubadoras que participaram da pesquisa da Anprotec (2012). ${ }^{12}$

Figura 1

Oferta de serviços e infraestrutura das incubadoras no Brasil em 2011

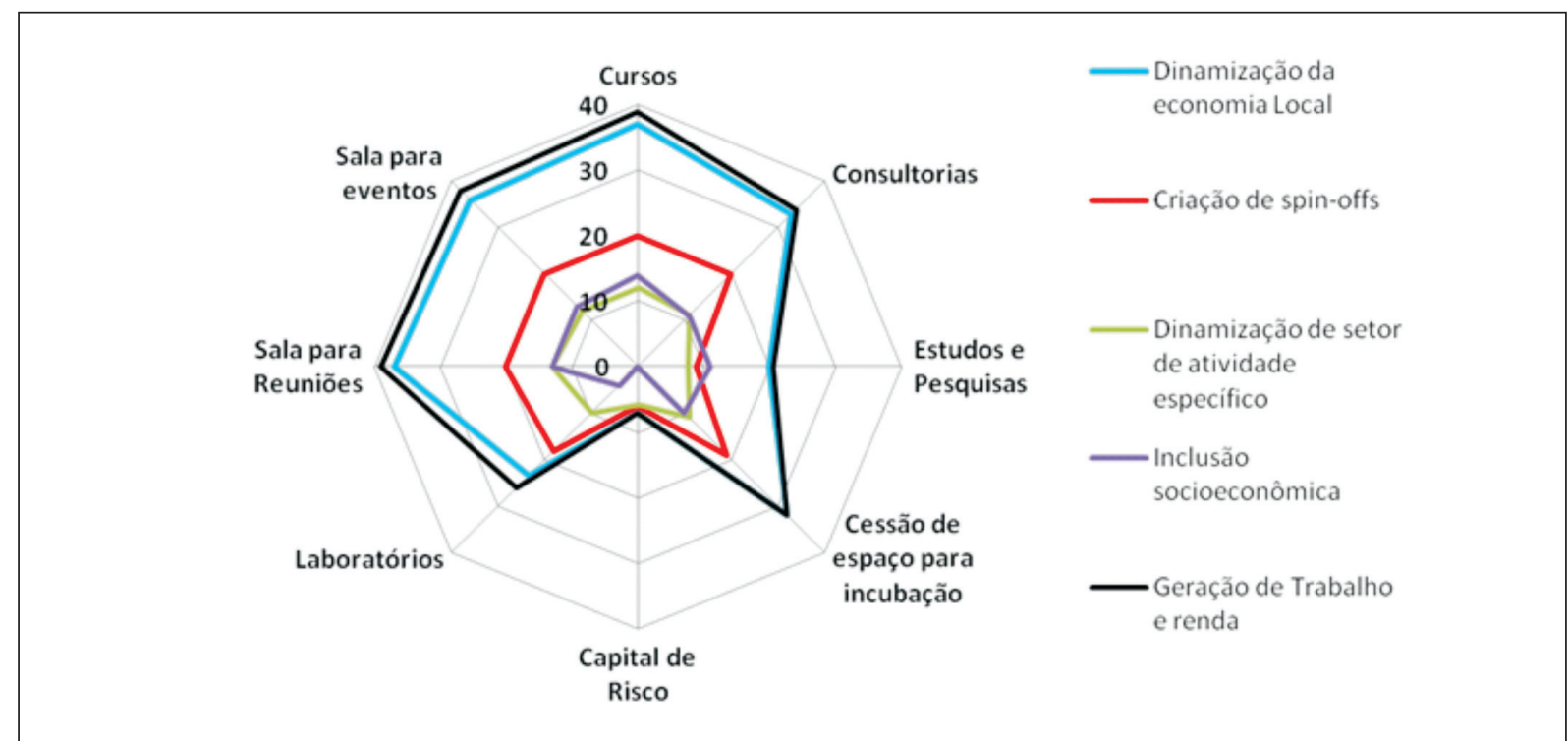

Fonte: ANPROTEC, 2012:13.

O segmento mais atendido pelas incubadoras no Brasil é o tecnológico (40\%), seguidos de mista (18\%) e tradicional (18\%); e de serviços (7\%) (ANPROTEC, 2012).

Observamos que o setor cultural não apresenta grande representatividade no universo das incubadoras nacionais, com apenas $2 \%$ do total em $2011^{13}$ (idem). Em 2005, existiam no Brasil treze incubadoras que apoiavam empreendimentos culturais (Zardo, 2005). A Incubadora Cultural do Instituto Gênesis da PUC-Rio é reconhecida como tendo sido a primeira iniciativa da América Latina. ${ }^{14}$ Criada em 2001, incorpora o conceito das indústrias criativas desde 2009. O Instituto ${ }^{15}$ já apoiou a geração de 68 empreendimentos criativos no Estado, 48\% do total de empreendimentos que o Instituto Gênesis apoiou desde sua fundação, há 18 anos. Desse universo, 18 empreendimentos integraram o Projeto Rio Criativo, concebido e implementado pelo Instituto Gênesis em parceria com a Secretaria de Estado de Cultura a partir de $2009^{16}$ (PUC-Rio, 2013).

12 As incubadoras que responderam à pesquisa da Anprotec em 2012 são responsáveis por mais de 2.500 empresas graduadas, que faturam $R \$ 4,1$ bilhões anuais e empregam diretamente mais de 29 mil pessoas. Já as empresas incubadas somavam mais de 2.600, apresentando 16.394 postos de trabalho e um faturamento de $\mathrm{R} \$ 533$ milhões (ANPROTEC, 2012:6).

13 Vale registro, no entanto, que tanto para o conceito de cultura ou das indústrias criativas, ou mesmo social, agroindustrial, há empreendimentos que atuam em setores difusos. Isto é, a pesquisa pode estar sendo minimalista ao associar os setores a apenas um dos setores identificados, não considerando que há, por exemplo, empreendimentos que atuam com TIC, mas que direcionam aplicados ao entretenimento, ao design, aos serviços, à educação, à agricultura etc.

14 Vale breve referência à história da Prana - Incubadora de Indústrias Criativas da Colômbia. Segunda na América Latina, criada em 2003 em parceria com British Council, é a mais relevante na região dado que, em 11 anos de existência, já gerou cerca de 500 empreendimentos criativos.

15 Em 2014, ganhou a nona posição do Global Top 25, ranking elaborado pela UBI Index, instituição de pesquisa sueca que avalia melhores incubadoras do mundo. Selecionado na categoria "Melhores Incubadoras Associadas a Universidades".

160 Rio Criativo foi concebido de março a outubro de 2009 e envolveu gestores da SEC, do Instituto Pereira Passos e da RioFilme, órgãos da Prefeitura do Rio de Janeiro, além do corpo gerencial e técnico do Instituto Gênesis da PUC-Rio. 
Os dados apontados complementam o perfil das incubadoras do setor cultural que têm, gradativamente, adotado a terminologia para as indústrias criativas, assim como se associam às novas incubadoras que já têm nascido com tal enfoque, como é o caso das iniciativas advindas do Programa Rede de Incubadoras Brasil Criativo do Ministério da Cultura (MinC).

Até o momento, o MinC já teria investido na Rede de Incubadoras Brasil Criativo R\$ 40 milhões e 13 novas incubadoras criativas teriam surgido no país, desde 2012, sendo estes os estados contemplados: Acre, Bahia, Ceará, Goiás, Mato Grosso, Minas Gerais, Pará, Paraná, Pernambuco, Rio Grande do Norte, Rio Grande do Sul, além do Distrito Federal e do Rio de Janeiro, estado em que o Rio Criativo é o representante de vanguarda da Rede que inclusive teria inspirado a criação da política nacional.

Esses dados reforçam a identificação de um novo enfoque das políticas públicas ao apostar na criação, no fortalecimento e na sustentabilidade de empreendimentos que atuam no setor criativo; tal perspectiva complementa as ações tradicionais das políticas de Estado para o setor cultural.

Esses novos agentes das políticas públicas - as incubadoras governamentais - lançam mão das opções corriqueiras de apoio a iniciativas culturais de seus empreendimentos culturais (há sempre um departamento das incubadoras direcionado ao apoio à elaboração e submissão de projetos das empresas incubadas para editais públicos e à legislação de renúncia fiscal), mas há incentivo de que as empresas incubadas busquem formas diferenciadas na relação com o Estado, com a sociedade como os agentes econômicos do mercado.

Entendemos que há um avanço com o surgimento das incubadoras, principalmente em escala. Atualmente muito mais gente no Brasil conhece o empreendedorismo e pode tomar a decisão por empreender com mais informação e apoio.

As incubadoras do setor criativo também passaram a representar, consequentemente, uma rede de empreendedores que podem se apoiar mutuamente, atuando como clientes e fornecedores deles mesmos; fortalecendo as MPEs criativas, as quais se configuram como a maioria do setor, segundo pesquisa da Firjan já apresentada.

\section{Rio Criativo}

O processo de incorporação à agenda setting fluminense pelo Estado se deu "com intuito de estimular o potencial da economia criativa para o desenvolvimento socioeconômico do Estado do Rio de Janeiro e a expressiva vocação cultural fluminense" (Rio de Janeiro, SEC/RJ, 2013). Isso é ratificado em dois trechos do Decreto da Secretaria de Estado de Cultura do Rio de Janeiro (SEC/RJ) que instaurou formalmente o Programa de Economia Criativa no Estado e que associa também caráter competitivo nacional e internacionalmente do Estado:

[...] a expressiva e histórica vocação do Estado do Rio de Janeiro como pólo nacional e mundial da Economia Criativa e seu potencial para o desenvolvimento socioeconômico fluminense; [...]; a estratégia intensiva de diversas cidades e países no mundo de atração de talentos [...]. (Rio de Janeiro, SEC/RJ, 2013, grifos nossos)

As ações da Incubadora do Instituto Gênesis da PUC-Rio se revelaram na gestão da Secretaria de Estado de Cultura do Rio de Janeiro (SEC/RJ) em 2009, tanto pela notoriedade da promoção de pesquisas de cadeias produtivas de segmentos que integram o setor cultural, como pela geração de empreendimentos criativos a partir da criação da primeira incubadora 
cultural da América Latina, em 2001, que, a partir daquele momento, passou a conviver com a incubadora tecnológica do Instituto.

Em 2014, encerrou-se o primeiro ciclo dessa política que ofereceu formação pública massiva em ferramentas de negócios a agentes do setor criativo do Estado, e serviço de incubação para empreendimentos cujos planos de negócios foram selecionados a partir de edital público. ${ }^{17}$

O pioneirismo e a inovação da iniciativa deveram-se à oferta de serviços especializados para implementação de planos de negócios criativos visando à geração, formalização e sustentabilidade de empreendimentos no setor criativo fluminense. Adicionalmente, a iniciativa inovou ao implantar a formação e qualificação ampla de empreendedores em temáticas relevantes que igualmente dão base ao desenvolvimento de iniciativas da área criativa para além da dinâmica e sazonalidade dos editais públicos.

Já as metas do processo de formação e qualificação pública atingiram cerca de 10 mil beneficiários nos cursos ministrados pelo Rio Criativo, desde outubro de 2010.

Conforme pode ser mais bem visualizado na Tabela 2, semelhantes foram os resultados do Núcleo de Incubação. Dos 80 empreendedores à frente dos 18 empreendimentos incubados, resultou-se em seis graduados ${ }^{18}$ e demais indicados para continuar com o processo de incubação por mais quatro meses.

Tabela 2

Desempenho dos empreendimentos incubados antes e depois do processo de incubação do Rio Criativo, agosto de 2012 a agosto de 2014

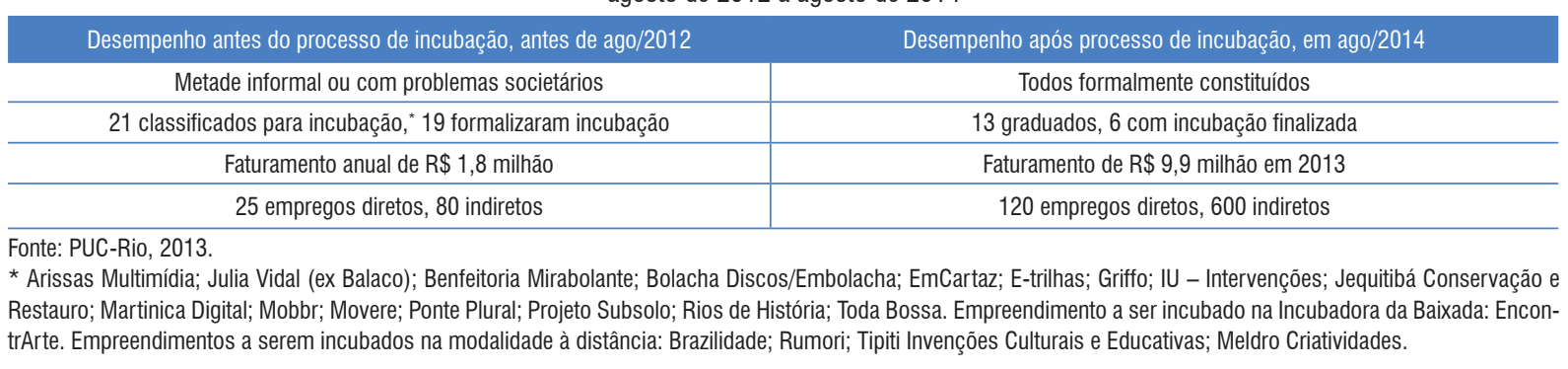

Como apresentamos, os resultados do projeto foram positivos em relação às expectativas definidas na política, mesmo a despeito dos diferentes "tempos" e "cuidados" processuais que a entidade executora (PUC-Rio) e a promotora (Estado) precisaram seguir; os quais nem sempre corresponderam à esperada resposta que agentes econômicos - empreendimentos incubados - teriam que imprimir no jogo do mercado inovador.

Mesmo assim, este fica registrado como um dos vários aprendizados dessa empreitada que temos o compromisso de documentar e reavaliar para apoiar processos semelhantes nacional e internacionalmente.

\section{Considerações gerais}

Pudemos observar a importância da atuação e sustentabilidade de MPEs por sua expressão nacional quanto ao nível de emprego e de geração de renda e riqueza no Brasil, além da sua associação direta com a competitividade nacional ao integrarem um ecossistema que vem sendo desenhado por diversas instituições há algumas décadas.

17 Em Mello e Zardo (2014) todo processo público seletivo e de formação é apresentado de forma aprofundada.

18 Rios de História, Mobcontent, Martinica, PontePlural e Movereme. 
Nesse contexto, tratamos da atuação histórica das incubadoras no apoio à sustentabilidade destes agentes econômicos. Vimos que, embora o universo das incubadoras no setor criativo seja ainda ínfimo em números absolutos, nos últimos dois anos duplicaram em número, passando de 13 a 26 incubadoras no Brasil graças à criação da Rede Incubadoras Brasil Criativo por parte do Ministério da Cultura, em 2013.

Como os novos entrantes não conseguiram ainda fechar um ciclo de incubação de seus empreendimentos incubados, o Rio Criativo se apresenta nacionalmente como projeto que tem se portado como laboratório para as demais iniciativas pelo objetivo audacioso, inovador e exitoso quanto aos seus objetivos previstos.

Como visto, a inovação desta iniciativa se deu principalmente pela oferta de serviços especializados para implementação de planos de negócios criativos visando à geração, formalização e sustentabilidade de empreendimentos no setor criativo fluminense. Logo, o edital do Rio Criativo não possibilitou obtenção de recursos financeiros diretos aos beneficiados, mas sim da disponibilização de tais serviços a partir da definição do que poderia melhor atender a cada um dos selecionados a partir de um sistema de apuração do desempenho dos incubados, considerando seus anseios, seus estágios e metas definidas e apuradas ao longo dos 18 meses de incubação.

O Rio Criativo e outras políticas que estão sendo implementadas nacionalmente nas últimas décadas têm ajudado sobremaneira na consolidação do termo das indústrias criativas e economia criativa no Brasil.

As novas políticas do setor cultural - as direcionadas ao setor criativo - podem inclusive ajudar no sentido de educar a relação do mercado no setor cultural, que historicamente atua via patrocínio privado quando da ação direta no mecenato. A forma pela qual isso acontece tem recebido críticas por parte dos agentes culturais pela postura tímida e reticente do empresariado brasileiro que exige valor alto como contrapartida e/ou limita seu aporte ao valor da renúncia tributária. O educar seria no sentido, por exemplo, de que os agentes do mercado repensassem esse comportamento e começassem a se relacionar como clientes e prestadores de serviço.

Entendemos que, por questões caras ao tradicional conceito de economia da cultura, têm sido levantadas discussões com frequência quanto ao aparente perigo de perda da espontaneidade das ações culturais e artísticas que poderiam se render à "pretensa instrumentação e diretividade associadas ao atendimento ao mercado".

Corroboramos com os que entendem que ambos os enfoques - o tradicional, relacionado aos editais e à renúncia fiscal, e o da economia criativa, em ações como a que vem sendo implementada por incubadoras de empresas do setor criativo - podem conviver no campo das políticas, até porque a intervenção direta governamental nunca será prescindida, considerando, por exemplo, a existência de produtos culturais não comerciais que integram a dimensão da cultura.

Falamos em conviver porque entendemos que o conceito de cultura carrega per se a potência de atuar como recurso e vetor de desenvolvimento socioeconômico, tanto por se caracterizar como identidade formadora de um povo, diferenciadora de territórios, como também por sua implicação com existência de indústrias criadoras de valores tangíveis e intangíveis na produção, distribuição e consumo de bens e serviços.

Que tal esforço orquestrado possa servir a anseios nobres da humanidade no sentido de aumentar as possibilidades de geração de renda e riqueza de forma sustentável ambientalmente, descentralizada e justa socialmente, ampliando o acesso e a distribuição dos seus resultados. 


\section{Referências Bibliográficas}

ADORNO, Theodor W; HORKHEIMER, Max. Dialética do Esclarecimento. Rio de Janeiro: Editora Jorge Zahar, 2006.

ANPROTEC - Associação Nacional de Entidades Promotoras de Empreendimentos Inovadores. Perguntas frequentes. Disponível em: < http://anprotec.org.br/site/pt/a-anprotec. Acesso em 10 maio 2014.

. Estudo, Análise e Proposições sobre as Incubadoras no Brasil, 2012. Disponível em: http://www.anprotec.org.br/ArquivosDin/Estudo_de_Incubadoras_Resumo_web_22-06_FINAL_pdf_59.pdf. Acesso em 29 jun. 2014.

AUSTRÁLIA. Creative nation: Commonwealth cultural policy. Outubro de 1994. Disponível em: http://apo.org.au/research/creative-nation-commonwealth-cultural-policy-october-1994. Acesso em 02 maio 2013.

BRASIL - Ministério da Cultura. Economia criativa cresce mais que o PIB no Brasil. Brasília, 05/09/2013. Disponível em: <http:/www.brasil.gov.br/cultura/2013/02/economia-criativacresce-mais-que-o-pib-no-brasil > . Acesso em 02 maio 2014.

. Plano Nacional da Secretaria da Economia Criativa, políticas, diretrizes e ações para 2011-2014. Edição revisada. Brasília Ministério da Cultura, 2011. 156 p. Disponível em www. cultura.gov.br/documents/10913/636523/PLANO+DA+SECRETARIA+DA+ECONOMIA+CRIATIVA/81dd 57b6-e43b-43ec-93cf-2a29be1dd071. Acesso em 10 maio 2014.

. Metas do Plano Nacional de Cultura. Brasília. Disponível em: < http://www.cultura. gov.br/plano-nacional-de-cultura-pnc->. Acesso em 03 maio 2014.

CALABRE, Lia. Política Cultural no Brasil: um histórico. In: CALABRE, Lia. (org.). Políticas Culturais: diálogo indispensável. Rio de Janeiro: Edições Casa de Rui Barbosa, 2005.

CUNNINGHAM, Stuart D. From cultural to creative industries: Theory, industry, and policy implications. Media International Australia Incorporating Culture and Policy. Quarterly Journal of Media Research and Resources, pp. 54-65. Available at: http://eprints.qut.edu. au/588/1/cunningham_from.pdf. Access 11 jul. 2014.

DCMS - Department for Culture, Media and Sport. Creative industries mapping document, 2001. Disponível em: <http://goo.gl/UsFid>. Acesso em 05 set. 2013.

DE MASI, Domenico. A emoção e a regra. 6. ed. Rio de Janeiro/Brasília: José Olympio/UnB Editora, 1999. 419 p.

FIANI, Ronaldo. Há uma "doença de custos" nas atividades culturais? Site Carbono, n. 4, set., 2013. Dossiê. Disponível em: http://revistacarbono.com/artigos/04-doenca-de-custosronaldo-fiani/. Acesso em 10 maio 2014.

FIRJAN - Federação das Indústrias do Estado do Rio de Janeiro. Mapeamento da indústria criativa no Brasil. Outubro, 2012. Disponível em: http://www.firjan.org.br/economiacriativa/ download/Analise_completa.pdf. Acesso em 01 maio 2014.

. A Cadeia da Indústria Criativa no Brasil. Estudos para o desenvolvimento do Estado do Rio de Janeiro, n. 2, Maio 2008.

FLORIDA, Richard. The Rise of the Creative Class. And How It's Transforming Work, Leisure 
and Everyday Life. Basic Books, 2002.

Folha se São Paulo. Cultura quer foco em economia criativa. São Paulo, 13 fev. 2011. Disponível em: <www1.folha.uol.com.br/fsp/mercado/me1302201102.htm>. Acesso em 02 maio 2014.

GARNHAM, Nicholas. From cultural to creative industries - An analysis of the implications of the "creative industries" approach to arts and media policy making in the United Kingdom. International Journal of Cultural Policy. Vol. 11, Issue 1, pp. 15-29, 2005.

HERSCHMANN, Micael. Lapa, Cidade da Música. Rio de Janeiro, Ed. Mauad X, 2007.

IBGE - Instituto Brasileiro de Geografia e Estatística. Sistema de informações e indicadores culturais: 2007-2010. n. 31. Rio de Janeiro: IBGE, 2013.

ISMAEL, Ricardo. Evolução do Orçamento Público e dos Incentivos Fiscais na Área Cultural: O Caso do Município do Rio de Janeiro. In: IV ENCONTRO NACIONAL DA ABCP - Associação Brasileira de Ciência Política, 24 jul. 2004.

ITC - Internacional Trade Center. Creative Industries. Disponível em: http://www.intracen. org/itc/sectors/creative-industries/.Acesso em 02 abr. 2014.

LANDRY, Charles. (2014). Entrevista para seção “Conte algo que eu não sei”, Jornal o Globo, p. 2, Rio de Janeiro, 06 jul. 2014.

LASTRES, H. M. M; CASSIOLATO, J. E. e MACIEL, M. L. (Orgs.). Pequena empresa: cooperação e desenvolvimento local. Rio de Janeiro: Relume Dumará Editora, 2003.

MELO, Sharine. As Políticas Culturais na atualidade e o trabalho em rede dos artistas. Rio de Janeiro: Fundação Casa Rui Barbosa, maio 2014.

MELLO, Ricardo F.; MELLO, R. E. S.; ZARDO, J. B. G. Productive Initiatives in the Realm of Creative Industries: A Territorial Approach of Two Brazilian Cases. International Journal of Business, Humanities and Technology, v. 4, pp. 56-64, 2014.

MELLO, Ruth E. S; ZARDO, J. B. G. Rio Criativo: política pública de formação, qualificação e de incubação de empreendedores nos setores criativos do Estado do Rio de Janeiro. Fundação Casa Rui Barbosa: Rio de Janeiro, maio 2014.

MELLO, Ruth E. S; ZARDO, J. B. G. (2013). Rio cidade criativa: economia criativa e ambientes para o desenvolvimento. Plurimus Cultura e Desenvolvimento em Revista, v. ii, p. 21-125, 2013. Disponível em: < plurimus.dominiotemporario.com/doc/Ed_III_completa.pdf >, acesso em $02 / 02 / 2014 a$.

MIGUEZ, Paulo. Economia criativa: uma discussão preliminar. In: NUSSBAUMER, Gisele Marchiori (Org.). Teorias e políticas da cultura: visões multidisciplinares. Salvador: EDUFBA, 2007. Coleção CULT, 1. pp. 96-97.

ORTIZ RAMOS, José Mario; BUENO, Maria Lucia. Cultura audiovisual e arte Contemporânea. São Paulo em Perspectiva, v. 15, n. 3, São Paulo, jul. 2001.

PUC-RIO - Pontifícia Universidade Católica do Rio de Janeiro. Instituto Gênesis. Relatório Anual de 2013. Rio de Janeiro, PUC-Rio, 2013.

REIS, Ana C. F. Evolução Histórica: da indústria criativa à economia criativa - pequeno panorama global. Cadernos de Economia Criativa: Economia Criativa e Desenvolvimento Local. 
Reis, A. C. F e Deheinzelin, L.: Sebrae e Secult/ES, Vitória, 2008.

RIO DE JANEIRO. Secretaria de Estado de Cultura - SEC/RJ. Decreto $n^{\circ} 44.159$ - Dispõe sobre a constituição do Rio Criativo - Programa de Desenvolvimento da Economia Criativa do Estado do Rio de Janeiro, 2013.

SEBRAE - Serviço de apoio ao Empreendedor e Pequeno Empresário. Micro e pequenas empresas geram 27\% do PIB do Brasil. 2014. Disponível em: http://www.sebrae.com.br/sites/ PortalSebrae/ufs/mt/noticias/Micro-e-pequenas-empresas-geram-27\%25-do-PIB-do-Brasil. Acesso em 27 jul. 2014.

SELTZER, Kimberly. The Creative Age: Knowledge and Skills for the New Economy. Demos, 1999. $91 \mathrm{p}$.

SOUZA, Mauricio Rodrigues de. O conceito de esclarecimento em Horkheimer, Adorno e Freud: apontamentos para um debate. Psicologia Social, Florianópolis, v. 23, n. 3, dez. 2011.

UNESCO - Organização das Nações Unidas para a Educação, a Ciência e a Cultura. Declaração Universal sobre a Diversidade Cultural, 2002.

UNCTAD - Organização das Nações Unidas para o Comércio e o Desenvolvimento. Creative Economy Report 2008: the challenge of assessing the creative economy, towards Informed Policy-Markers. 2008.

UK - United Kingdom Government. The UK Policy Environment. Disponível em: http://creativeconomy.britishcouncil.org/Policy_Development/policy-environment. Acesso em 02 abr. 2014.

Valor Econômico. Entrevista com Sérgio Sá Leitão no artigo "Estado deve dinamizar, e não inventar a cultura”. 2012. Disponível em http://fndc.org.br/clipping/entrevista-sergio-sa-leitaoestado-deve-dinamizar-e-nao-inventar-a-cultura-852461. Acesso em 02 abri. 2014.

XAVIER, Sérgio. Cultura digital e redes colaborativas: oportunidades para empreendedores criativos. Cadernos de Economia Criativa: Economia Criativa e Desenvolvimento Local. Organizadoras: Ana Carla Fonseca Reis e Lala Deheinzelin: Sebrae e Secult/ES, Vitória, 2008. p. 19.

YUDICE, George. A conveniência da cultura: usos da cultura na era global. Belo Horizonte: Editora UFMG, 2006. 615 p.

. Revista Z Cultural - Revista virtual do Programa Avançado de Cultura Contemporânea, Ano IX, Número 1. Heloisa Buarque de Hollanda entrevista George Yudice, ago. 2005. Disponível em: http://revistazcultural.pacc.ufrj.br/heloisa-buarque-de-hollanda-entrevistageorge-yudice-agosto-de-2005-2/. Acesso em 10 jul. 2014.

ZARDO, Julia B. G. Comunicação, cultura e desenvolvimento local - Conservatória (RJ), um estudo de caso. Dissertação de mestrado na ECO/UFRJ. Rio de Janeiro, 2006.

. Do Negócio da Cultura à Cultura dos Negócios. Um Guia para Planejamento e Gestão. Brasília, Anprotec e Sebrae, 2005. 